\title{
Early marriage as a barrier to the career and educational opportunity for the youth in Georgia
}

Magda Rukhadze ${ }^{1}$

${ }^{1}$ Faculty of Social and Political Sciences,Department of Sociology,Tbilisi State University.

\begin{tabular}{l} 
ARTICLE INFO \\
\hline Keywords: \\
early marriage \\
youth \\
education \\
career \\
barrier
\end{tabular}

\begin{abstract}
Early marriage is an official or unofficial relationship between two people when at least one of them is less than 18 years old. Various factors have an impact on early marriage such as traditions, norms, gender inequality, financial status, an attempt to avoid loneliness especially in families where parents are divorced, or adolescents have family duties. The survey aims to study the effect of early marriage on education and career opportunity of adolescents. The survey was conducted with 45 respondents ( 28 women and 17 men). The findings show that early marriage is a barrier to education, which later reduces employment opportunist as well. Adolescents have positive attitudes towards education, but only $1 / 5$ of them were able to continue their study after marriage. About $85 \%$ of adolescents do not have a job, but they receive essential financial and psychological support from their parents. The majority of respondents do not have any specific plans to continue their study. However, they hope that in the future they will be able to get an education and be employed. One of the crucial factors for preventing early marriage is raising of awareness of adolescents, their parents, families, and society about the issues such as risks of early marriage, family planning, etc. Besides, it is impotent to provide information and services to adolescents to support their participation in education, improve their employability opportunities and social integration.
\end{abstract}

\section{Introduction}

Early marriage is an official or unofficial union between two people, one of which is less than 18 years old.

Early marriage is a complex of the phenomenon, and various factors have effects on it, such as gender inequality, poverty, traditions, and insecurity. In many countries where child marriages are more common, girls are not as valued as boys. They often consider girls as family burdens. Early marriage is often transferred from generation to generation and becomes a cultural phenomenon. Early marriage for low-income families means improving economic conditions; Early marriages are especially common in developing countries where urbanization index is low, and society protects old traditions. Such countries are mainly in Asia and Africa. The age of 
marriage varies by country, although this period is between 16 - 20 years. According to the Civil Code of Georgia, marriage is allowed from the age of 18 , when the person is considered to be adult.

In countries with a high risk of safety, early marriages are the only way to protect the girls. These factors vary by countries and regions.

In general, the early marriage rate is reducing worldwide, although it is a slow process in many developing countries; In 2017, 70 million women aged 20-24 were married before 18 years (Mahato, 2016). Moreover, in developing countries, 1 out of every seven girls was married under 15 (Rodgers, 2012). For instance, early marriages in Nigeria is about 75\%, followed by Central Africa (68\%) and Bangladesh (66\%) (Ahmed,2015).

Early pregnancy leads to health risks, particularly among girls such as premature labor and reproductive health. It is also important to consider risks associated with psychological, emotional and social development. Early marriages are also related to domestic violence. It is known that most of the cases of violence occur in the families created at an early age. Such families are dependent on parents. In general, early marriage is undesirable. The pair is often not ready for the family life and responsibilities. In many cases, early marriage is associated with discontinued education, frustration, lack of career progression and social problems. In many cases, girls are only able to continue their studies if their spouse's family allow it.

Early marriage may be considered as child abuse because the adolescent will not get an informed decision; Especially if marriages are made by force.

Early marriage, especially for women, contains socioeconomic risks; Among them are reduced access to education and employment opportunities - early marriage in all countries of the world has an impact on the education of girls. Generally, early marriage promotes social vulnerability. The higher is the level of education for girls; the lower is the early marriage rate. In general, the number of girls in early marriage worldwide is much more than boys. Although girls are more vulnerable to early marriages than boys, the negative impact of early marriage is not limited only to them, but it is more extensive and includes family and community.

Access to education is closely linked to employment; Due to the lack of skills and competencies for employment, young adults in early age find it difficult to get a stable and wellpaid job. Their income is low, and the job is unstable - that way, they face economic problems that make them depended on others.

At the age of adolescence, pregnancy and childbirth are risk factors for girl's health. According to UNFPA ("Motherhood in childhood,2013), More than 7 million young girls were pregnant; it about 2 million of them was under 14 years; in developing countries about 70,000 adolescent girls die from pregnancy.

\section{Case of Georgia}

According to reproductive, physiologically human organism can be ready for the marriage at the age of 14-16, but its social and psychological maturity is achieved later.

In Georgia, early marriage is one of the highest in Europe. Although early marriage often is not officially registered and there is no exact statistics. So we should assume that this number is much higher (UNFPA, 2017). According to the data of 2014, the percentage of early marriage in Georgia was $18 \%$. According to the information provided by the Ministry of Justice of Georgia, marriages of 611 juveniles were registered in 2015, and 665 in 2014. About 95\% of them were girls. According to 2013 data, Georgia took the second place after Moldova, according to the early marriage of girls. 19\% of girls between 20 and 24 years were married before 18 years. According 
to the UNFPA survey, which was conducted with 324 respondents aged 12-34, 14\% of 20-24 years of age created the family until the age of 18 . Early marriages index is almost five times less among men.

According to the Public Defender's Report (2016), Ministry of Education and Science informs that until the end of the public and private schools, in the 2015 year 408 adolescents aged 13-17 dropped out from education because of the marriage, and 1449 of them became parents.

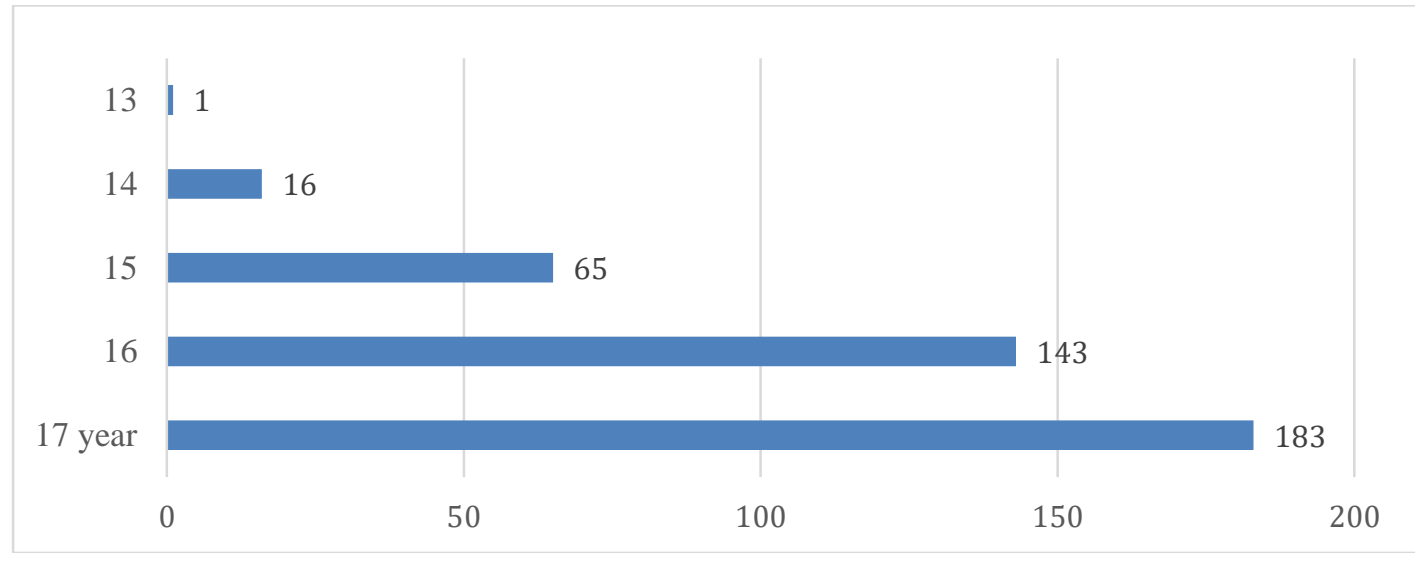

Diagram N1 number of dropouts during 2015 for marriage (Public defender`s report,2016)

It should be mentioned, that the highest rate of early marriages is in Tbilisi and is equal to 393.

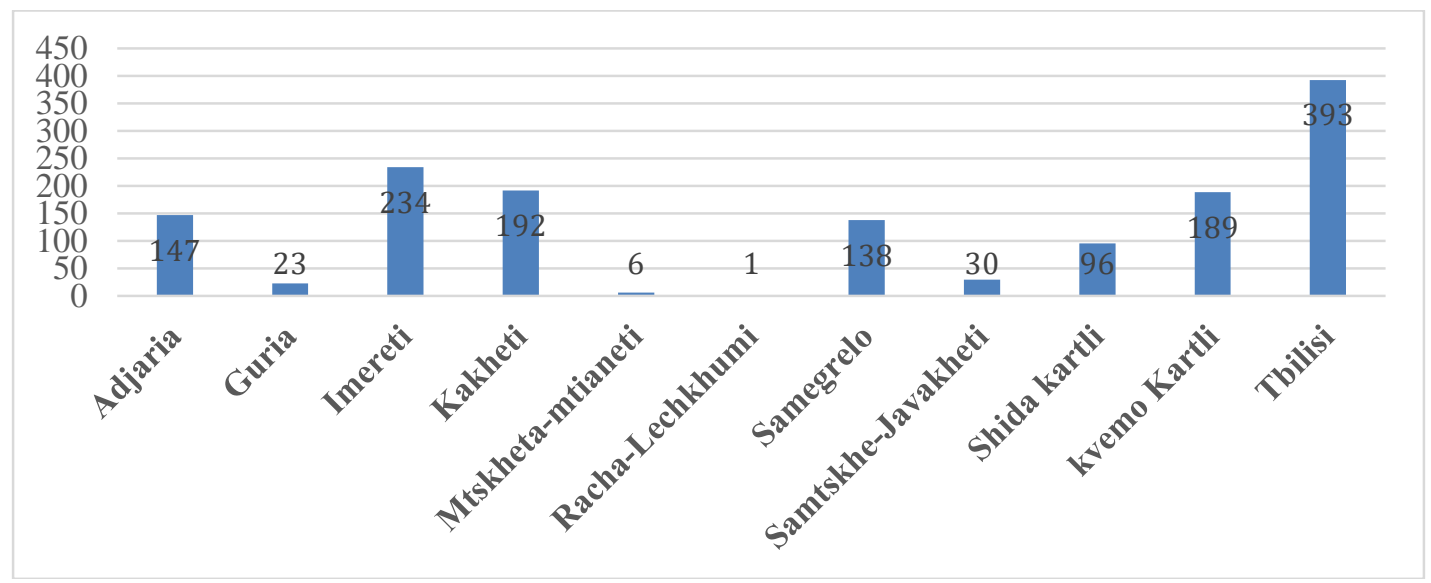

Diagram N2: Early marriages by regens (2015)

From January 1, 2016, the Law was revised, according to which the parents' consent permitted the marriage of persons reached at the age of 16. This change in legislation was taken into consideration by the recommendation of the Committee on the Elimination of the United Nations Discrimination Committee (CEDAW). From 2017 marriage of persons under 18 is prohibited by the law.

Early marriage in Georgia is not only related to traditions and ethnic minority groups as it was considered before. It is a widespread phenomenon in the whole country. In Georgia, there are not many studies conducted on this topic as well as accurate statistics are not available. 


\section{Research methodology}

A semi-structured interview was conducted with 45 respondents in Tbilisi who have created the family till 18 years; 28 were women, and 17 were men; Average age was 21 (minimum 19, maximum 24). The study was conducted in May-June 2018 using a specially designed instrument.

\section{Research results}

The reasons for marriage and the satisfaction of marriage

The research identified the following reasons of early marriage: the norms that restrict young people to have boyfriends / girlfriends (49\%); expectation of improvement of financial conditions (36\%), to escape from loneliness - especially in families where parents are divorced and/or if they take care of their brothers(24\%).

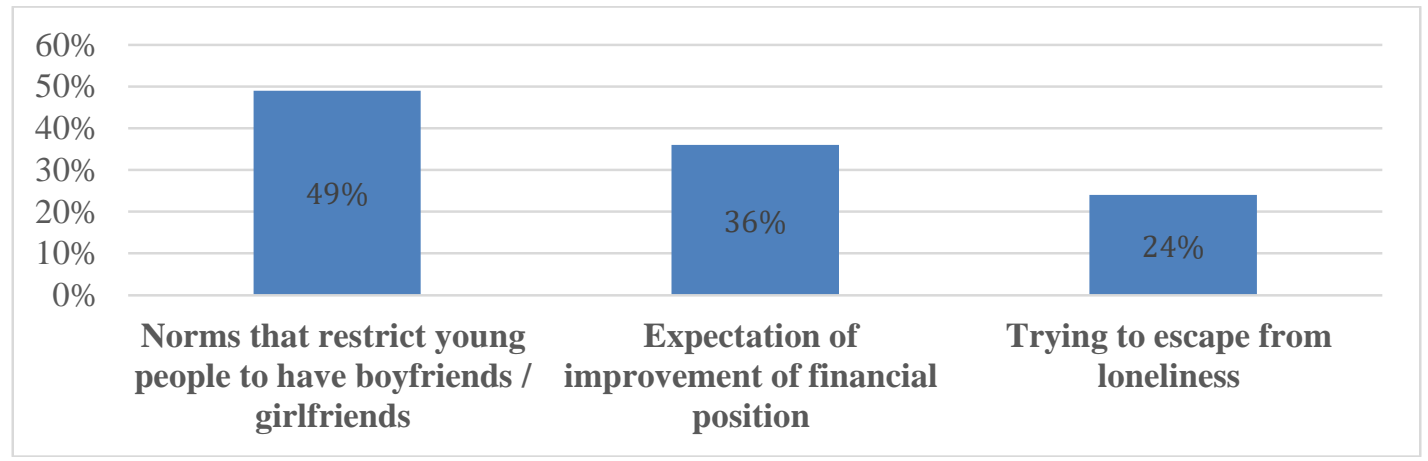

\section{Diagram N3: Reasons for early marriage}

According to the study, the couple had a short time relationship before marriage; $91 \%$ of respondents negatively assess the fact that they did not know the well future spouse, his/her daily lifestyle, family, friends. Before the marriage, none of the respondents had intimate relations with the future spouse because of Georgian traditions.

For about $76 \%$ marriage restricted their freedom. They became accountable firstly to their husbands and secondly to their mothers-in-law and finally to other family members. They said their parents were more supportive of them than new family members of their spouses.

None of the respondents had planned to be married. $96 \%$ did not have any information about family planning or reproductive health. They decided to marry, spontaneously. They did not have information about future family responsibilities. According to their narratives, the couples do not have common interests, and their family life has become an obligation. "I was expecting something different! I did not think we would be a normal couple "(20 years old girl). $75 \%$ of respondents indicated the changing of relations.

The girls also emphasized their obligations. It was difficult for them to adapt to their obligations: "First there was love, then motherhood, it is awful; I love the baby very much, but I never thought I would have a 7-year-old son at this age; he is too big for me" (Girl-23 years old). "I think that if you create a family at an early age, you get old. This is a big burden. I have three 
children, and I cannot recognize myself in the mirror; I become jealous when my peers only care about learning. If I go somewhere, I feel guilty that kids are waiting for me (22 years old girl). "

Education, attitude towards education and plans

$91 \%$ of respondents wanted to get a good education and have a good job. Career development was essential for them. As mentioned above, marriage and childbirth were not among their plans. "I used to study all the time, I had never wanted to get married, then I've got to know" $\mathrm{b}$ "and everything changed. After the wedding I wasn`t thinking about continuing my studies, so I stopped; Now I think that "I'm getting stupid" (22-year-old girl).

It should be mentioned that only $20 \%$ of respondents continued study in higher education, while others did not have the opportunity to do so. The respondents said that their spouses were more unserious about education. Some of them even did not graduate from high school. Husbands mostly were not against their wives to get an education.

In 5 cases, the spouse and the mother-in-law did not allow girls to study in higher education institution; at the same time husbands of these girls did not have a job or education and were materially depended on the family.

Education is essential for the respondents; They have a positive attitude toward education; Education is an essential prerequisite for employment; Education is one of the most critical factors for maintaining personal relationships: "Then, how to say, after a school you still have a different view of life than those who only graduated from school" (boy-24 years old). Some respondents who are dissatisfied with their spouse's education indicate that this fact played a significant role in their relationships because the educated man evaluates the problem/situation more effectively and tries to solve them, controls emotions and respects his wife.

Except for $20 \%$ who have continued their studies, the rest of the respondents did not have any specific plans, but most of them hoped that they would learn something and become employed.

\section{Employment}

$85 \%$ of respondents did not have a job and a stable income but were supported by parents. Economic problems were one of the primary reasons for disagreement. The girls noted that their families had a better financial condition than their spouses' families. Parents who had a good income supported their children: " I was supported all the time, now when I remember my childhood I miss that time" (girl-21 years old). "When I see my new house ... where should I live, I started regretting about my decision" (girl-24 years old). As girls noted they were more motivated to be employed than their husbands. "I chose vacancies for him, but he did not go to interview" (20 years old)."

It can be said, that the female representatives take care more about family life and try to think about the prospects of the family than their husbands.

\section{Support}

About $80 \%$ of respondents report that they receive significant financial and psychological support from parents. They were always trying to support their children in awkward moments and insisted them not to divorce.

None of the parents of the survey respondents were married until 18 years. The biggest part of the parents was against early marriage, "my mother said, what would society say about me or my family? That I am not educated enough and I let my daughter marry at this age? How can I explain everything? ". But because the children chose this way, they felt that they should help 
them. The most supportive were parents of girls: "If my daughter my had done this, I wouldn't have forgiven her. It seems that my mother loves me so much that she forgave me helps me. She is 41 years old and she is doing everything only for me not take care of her "(Girl-24 years old).

Respondents mentioned that they thought that marriage would hold them to solve their problems. Some of them thought that marriage would help them not feel loneliness.

\section{Conclusion}

The study shows that the couple has made a hasty decision about their marriage and they regret it. Young people did not know each other well; they had less information about the future spouse's interests, material welfare, motives.

The significant problems are a lack of financial resources and increased family responsibilities, especially for girls. Early marriage is a barrier to education, which further reduces the employment of adolescents.

Young people have a positive attitude toward education, but only $1 / 5$ of them managed to continue their studies. The rest does not have specific educational plans, but most people hope to get an education and get employed. Unemployment makes young families dependent on parents. Although none of the parents of the adolescents were in favor of their marriage, they give significant psychological and financial support to young people.

The study shows that it is essential to support the implementation of the law, according to which marriage is permitted from the age of 18. It is important to raise awareness of young people, their parents, families, the general public about the risks of early marriages, family planning, reproductive health. In addition to providing relevant information and support services. It is recommended to increase access to education for the adolescents in marriage, to support their employment and social inclusion in general. It is also recommended to carry out systematic research and develop evidence-based policy and measures of early marriage prevention and intervention.

\section{References}

1. Ahmed, T (2015). Child Marriage: A Discussion Paper. Bangladesh Journal of Bioethics ; $6(2): 8-14$

2. Letter of the ministry of justice \#7265/2309.2015

3. Mahato, K. (2016)Causes and Consequences of Child Marriage: A Perspective. International Journal of Scientific and Engineering Research. 698-702

4. Nour, N. M. (2009). Child marriage: A silent health and human rights issue. Reviews in Obstetrics and Gynecology,2(1),51-55.

5. Public defender's report 2012, pages 5-9

http://www.parliament.ge/uploads/other/75/75677.pdf

6. Rodgers, B. (2012). Child marriage in Ethiopia and its associated human rights violations. Policy Journal, 11-12.

7. The Civil Code of Georgia, Parliament of Georgia,1997

8. UNFPA, Georgia - Early Marriages, Research (UNFPA)

http://www.calameo.com/books/000713529423e3af16ad7

9. UNFPA "Motherhood in childhood" ,2013 pages 17-3 